\title{
Measures to ensure road traffic safety on controlled intersections
}

\author{
Aleksandr Novikov ${ }^{1, *}$, Ivan Novikov ${ }^{2}$, and Anastasiya Shevtsova ${ }^{2}$ \\ ${ }^{1}$ Orel State University, 302026 Orel, Komsomolskaya st. 95, Russian Federation \\ 2 Belgorod state technological University named V.G. Shukhov \\ BSTU named V.G. Shukhov, 308012 Belgorod, Kostyukova str., 46, Russian Federation
}

\begin{abstract}
The paper discusses a new approach to ensuring the safety of controlled intersections. In the course of research, the authors found a change in the main characteristics of the traffic flow, which requires constant monitoring in the implementation of the intersection control using a traffic light. The heterogeneity of the composition of the traffic flow is determined and the influence of this parameter on the duration of the resolving signal is established. In addition, the authors determined the influence of weather conditions on the duration of the traffic light cycle and developed an approach to take into account changes in this factor in the calculation of the mode of operation of the traffic light object. As a result of the model experiment, the economic and environmental efficiency of the developed approach is determined. The results obtained in the course of the study are an integral part in the implementation of intelligent transport systems, which confirms the relevance and feasibility of the study. The use of this approach, in addition to integration into the its system, allows to reduce the accident rate of controlled intersections due to the rational distribution of the time of the traffic light object and reduce vehicle delays on the approaches, which together ensures the safety of regulated areas.
\end{abstract}

\section{Introduction}

Today, we all face transport problems that are common to many world countries. Every year, government funding is allocated to solve these problems, and targeted programs are developed to partially reduce traffic accidents. In the Russian Federation to solve the transport problems of developed transport strategy and transport program [1,2], which are designed for long-term period up to 2030 and 2020, respectively, due to the fact that the decision is not defined local actions and targeted incremental stages. The goals of the state program reflect the final results of solving transport problems of the Russian Federation socio-economic development for the period up to 2020 [3] and EU [4] In order to further the modernization of the transport system in 2011, the EU adopted a special road map [5], which includes the main directions of development of transport infrastructure of EU Member States and covers the period until 2050.

\footnotetext{
* Corresponding author: novikovan57@gmail.com
} 
The key solution to the issue of transport problem is the introduction of intelligent transport systems. In this regard, it is necessary to develop traffic safety methods at regulated intersections that can be integrated into ITS [6].

\section{Accounting for heterogeneity in the composition of the traffic flow}

In the Russian Federation, in the field of traffic safety, an integrated approach is used for a long-term period, reflected in the main regulatory document [7]. Special attention today is paid to intelligent transport systems that need to be integrated into the existing environment using micromodelling.

To perform the study, the author group uses a specialized software product [8].

According to official statistics [9] the number of the vehicle fleet for 2018 is more than 55 million units between 2002 and 2018, this figure increased more than 2 times (fig. 1). It should be noted that most of the fleet registered passenger cars up, the main advantage of which is compared with other modes of transport is the mobility and comfort.

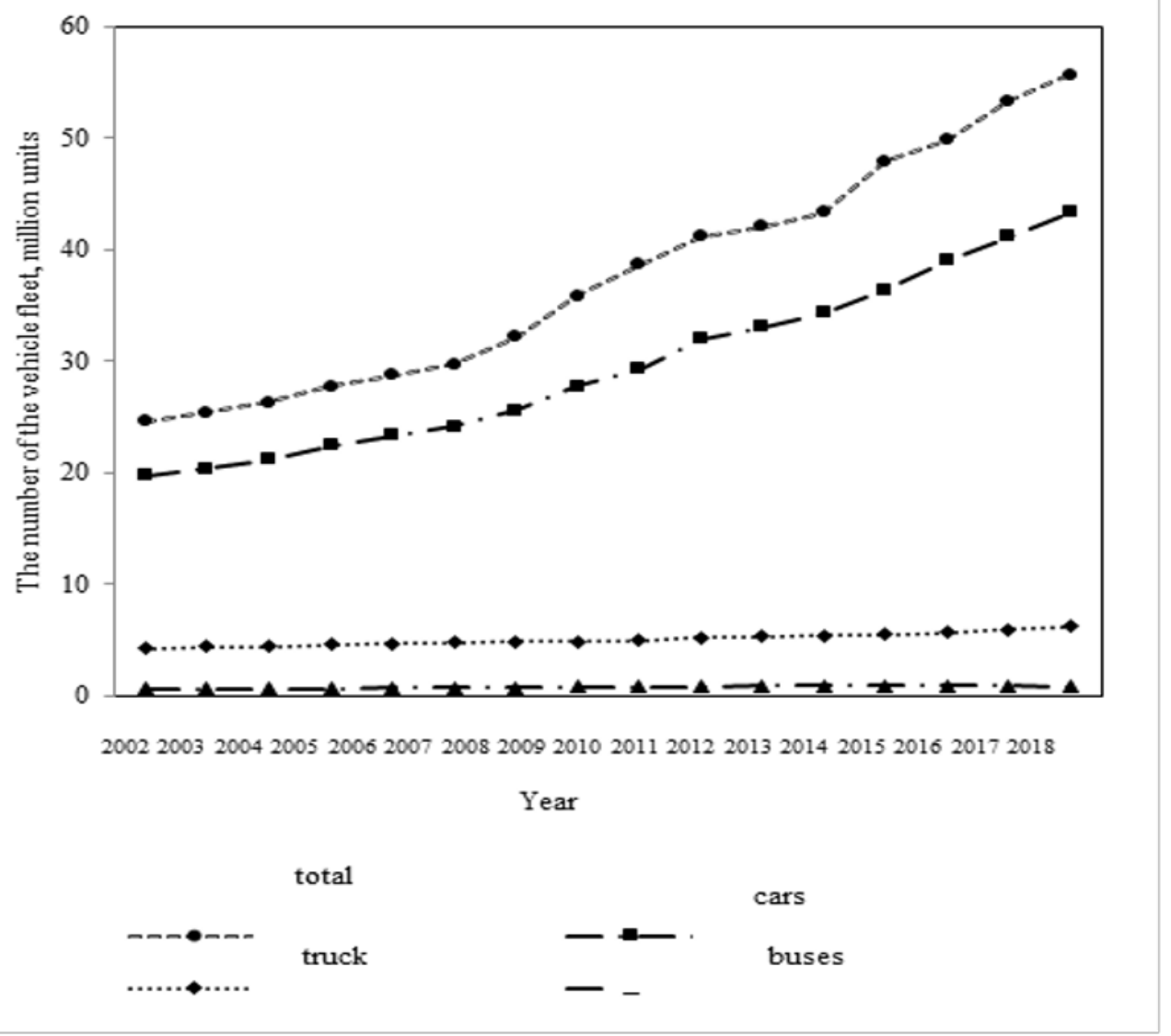

Fig. 1. Graph of the number of cars in the Russian Federation for the 2002-2018 years.

Over the last 20-30 years and to modify the park itself the most popular vehicles - cars, underwent considerable modification dimensional parameters of vehicles on the road often have to meet such as cars mini-cars and a jeep. According to the generalized analysis of the works of Russian scientists Yakovlev V.F. [10] Porvatova I.N. and Crystal S.R [11] for the 
separation of passenger cars on the basis of the dimensional - overall length using Western European classification (tab. 1).

Table 1. Western European classification of cars.

\begin{tabular}{|c|c|}
\hline Designation class & Vehicle length, $\mathbf{m m}$ \\
\hline A & before 3500 \\
\hline B & from 3500 before 3900 \\
\hline C & from 3900 before 4300 \\
\hline D & from 4300 before 4600 \\
\hline E & from 4600 before 4900 \\
\hline F & more 4900 \\
\hline
\end{tabular}

As a result of the analysis of scientific sources [12-14] allowed entry to conduct a study of traffic flows on the example of the regional centers of Belgorod and Orel region to reflect the bundle segment cars on classes. The use of introduced the concept of "factor presence" - reflecting the diversity of this type of rolling stock and is determined according to the formula:

$$
k_{A} \ldots k_{F}=\frac{\alpha_{A} \ldots \alpha_{F}}{100 \%}
$$

where $k_{A} \ldots k_{F}$ - factor the presence of each class of car; $\alpha_{A} \ldots \alpha_{F}-$ the percentage of each class of the car in the transport stream, \%.

According to the experimental analysis of the regional centers, the main transport stream up cars $(>90 \%)$ bundle that fully reflects the values obtained for the presence of factors (tab. 2).

Table 2. Values of coefficients for the presence of urban regional traffic flows cents Belgorod and Orel of the Russian Federation.

\begin{tabular}{|c|c|c|c|c|c|}
\hline $\mathrm{k}_{A}$ & $\mathrm{k}_{B}$ & $\mathrm{k}_{C}$ & $\mathrm{k}_{D}$ & $\mathrm{k}_{E}$ & $\mathrm{k}_{F}$ \\
\hline 0,15 & 0,11 & 0,35 & 0,13 & 0,11 & 0,14 \\
\hline
\end{tabular}

\section{Depending on weather conditions}

Weather and climatic conditions have a significant impact on traffic regimes and safety. The influence of this factor is especially noticeable at controlled intersections. The duration of cycles and phases red light alarm, designed for good driving conditions, are not effective in changing weather conditions. In this regard, the algorithms for passing vehicles need to be adjusted to take into account the weather and climate factors.

When calculating a traffic light object, the main value is the traffic intensity, the composition of the traffic flow and the saturation flow. The deterioration of weather conditions mainly affects the value of the saturation flow, so this parameter requires adjustment when changing traffic conditions.

The analysis of the research on the influence of climatic factors on the parameters of movement of vehicles [15-19] the authors established the dependence of the temperature of the ambient air with a temperature of asphalt pavement, which is connected with the coefficient of adhesion, which is necessary to calculate the cycle of traffic regulation. The minimum temperature of the coldest five-day supply of 0.98 in the city of Belgorod and the city 
of Orel is $-27^{\circ} \mathrm{C}$. For the city of Belgorod and Orel, the average annual temperature is at $6.4^{\circ} \mathrm{C}$.

Having determined the necessary temperature values, the maximum $\mathrm{T}_{\mathbb{d}}^{\max }$ and the minimum $T_{\mathbb{d}}^{\text {main }}$ of the asphalt concrete coating temperature are determined:

$\mathrm{T}_{\mathrm{d}}^{\mathrm{min}}=0,859 \cdot(-27)+1,7=-21,5^{\circ}$

$\mathrm{T}_{d}^{\max }=-0,0306 \cdot 38^{2}+3,8071 \cdot 38-39=61,5^{2} \mathrm{C}$

Using the obtained temperature values, the dependence of the asphalt concrete coating temperature on the ambient temperature is obtained (fig. 2).

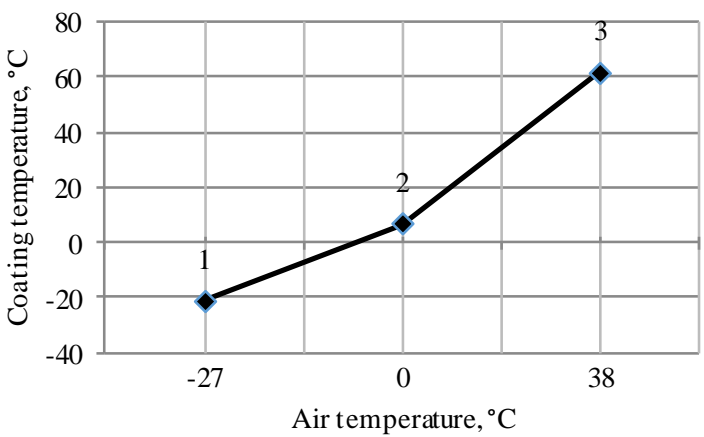

Fig. 2. Dependence of the calculated surface temperature of asphalt concrete coating on the ambient temperature for Belgorod and Orel.

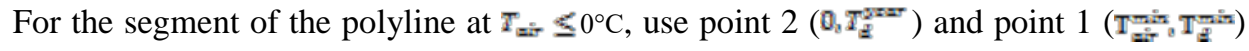
as given, for the segment point $2\left(T_{a r}>0\right)$ and point $3\left(\mathrm{~T}_{\min }^{\min } \mathrm{T}_{\overrightarrow{d i n}}^{\min }\right)$. Thus, the equations of lines acquire the following general form:

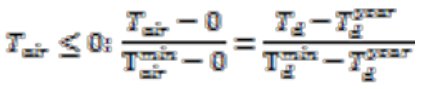

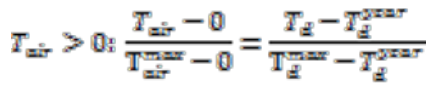

Transforming the resulting equation and substituting in them the values of the corresponding temperatures, get the dependence describing the relationship of the temperature of the asphalt pavement and ambient air temperature on the territory of the city of Belgorod and the eagle. In this connection, the values of the coefficient of adhesion for different ambient temperatures were obtained:

$$
\begin{aligned}
& \text { 1. }-20^{\circ} \mathrm{C} \ldots-10^{\circ} \mathrm{C} \rightarrow \varphi=0.4 \\
& \text { 2. }-9^{\circ} \mathrm{C} \ldots-5^{\circ} \mathrm{C} \rightarrow \varphi=0.3 \\
& \text { 3. }-4^{\circ} \mathrm{C} \ldots-3^{\circ} \mathrm{C} \rightarrow \varphi=0.2 \\
& \text { 4. }-2^{\circ} \mathrm{C} \ldots 0^{\circ} \mathrm{C} \text { (inclusively) } \rightarrow \varphi=0.1 \\
& \text { 5. } 0^{\circ} \mathrm{C} \ldots 1^{\circ} \mathrm{C} \text { (inclusively) } \rightarrow \varphi^{\varphi}=0.3 \\
& \text { 6. } 1^{\circ} \mathrm{C} \ldots 2^{\circ} \mathrm{C} \rightarrow \varphi^{\varphi}=0.5 \\
& \text { 7. } 3^{\circ} \mathrm{C} \text { до } 5^{\circ} \mathrm{C} \rightarrow \varphi^{\varphi}=0.6 \\
& \text { 8. } 5^{\circ} \mathrm{C} \text { and above } \rightarrow \varphi^{\varphi}=0.65-0.7
\end{aligned}
$$




\section{Method of calculation and its introduction in the ITS component}

Previous studies have shown that the setting - overall length has a significant effect when using forced control - traffic lights, namely, per the resolution of the signal duration [2022]. Using past experience, the research group is common in the Russian Federation procedure of control cycle has been improved (fig. 3).

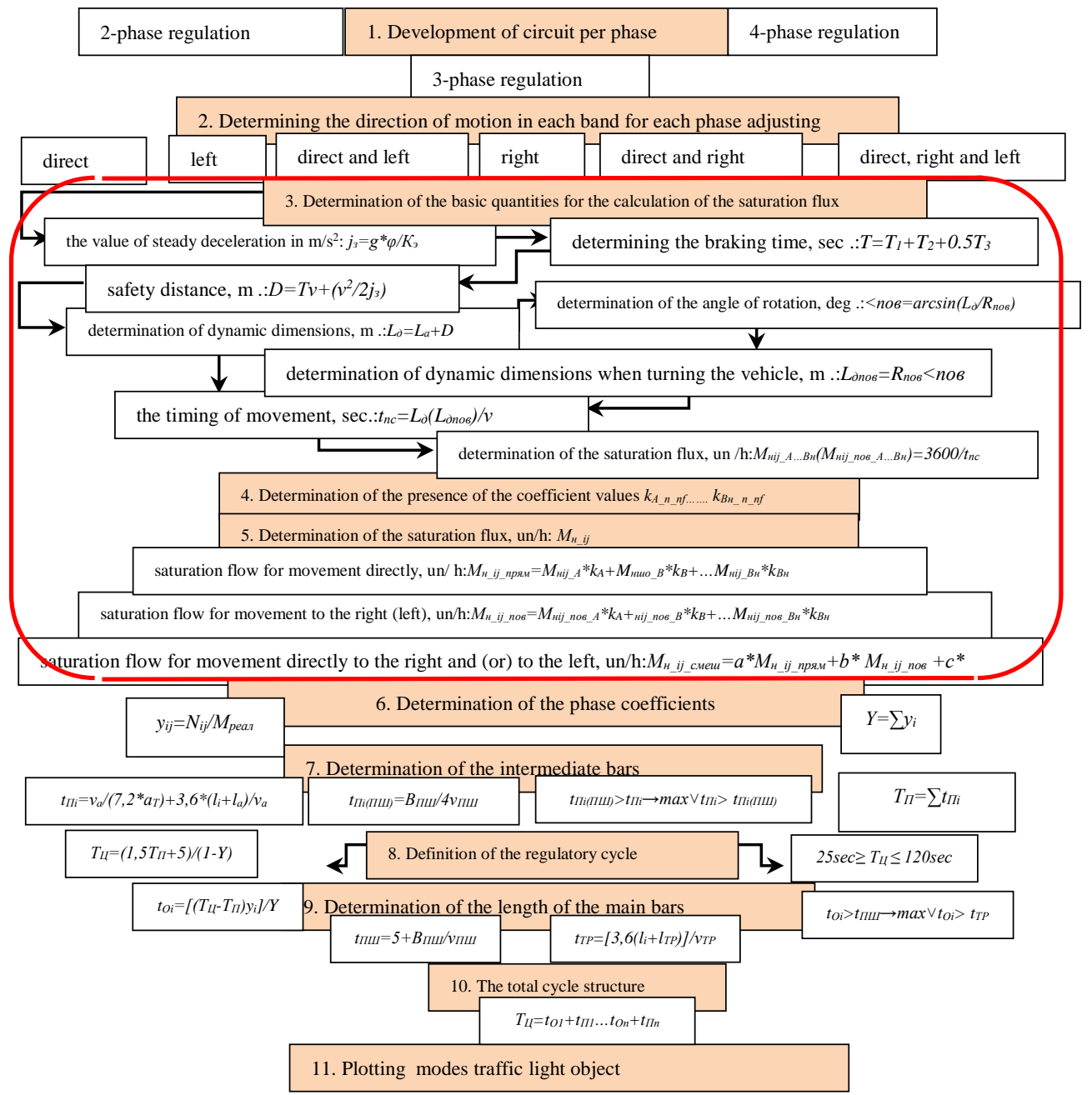

Fig. 3. Implementation of the proposed parameters.

Implementation of the developed technique must be integrated, which will reduce unintended stopping of vehicles, developed under the ploy is to integrate subsystems for advanced traffic monitoring traffic flow characteristics in the structure of ITS (fig. 4). 


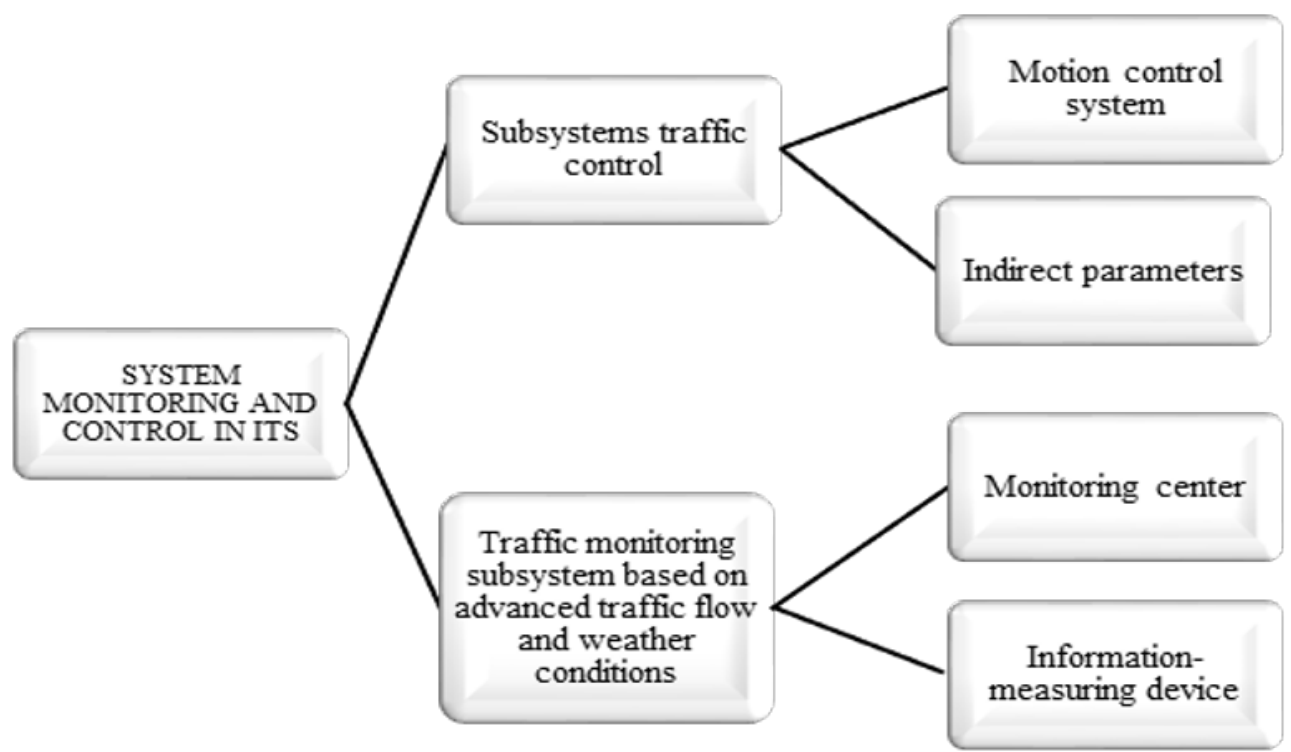

Fig. 4. ITS integration system.

Building subsystem traffic monitoring on the advanced features of traffic should be conducted together with the basic infrastructure facilities, as controlled parameters used for monitoring are the characteristics of the advanced characteristics of the traffic flow: the intensity, the presence of each class of car, the coefficients of presence, high-speed mode, the composition, and the characteristics of quality traffic control (presence and type of intersections, stopping points, the number of intersections with traffic regulations, the ratio of the duration of the different phases of traffic lights, the level of the roadway, and the availability of automated traffic management tools).

\section{Experiment}

In order to evaluate the proposed methodology to the development of computer experiment performed using Transyt -14 TRL software using modeling signaled intersection in the center of the regional network editor (Netcon) performed (Fig. 5).

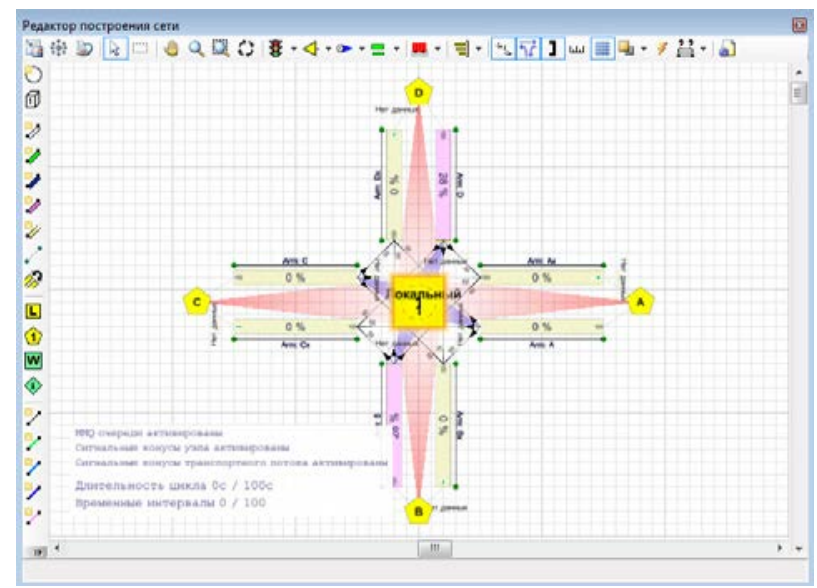

Fig. 5. Simulation signaled intersection in Transyt 14 TRL. 
Using advanced technique (Figure 2) and obtained during the experimental analysis of the coefficients of presence (Table 2) Calculate the required duration of the regulatory regime and the analysis made to the existing regime on the main characteristics of the transport stream obtained in the course of the simulation: stops and delays; queues and congestion; fuel consumption.

Performance indicators on average improved in all of the above indicators by $12 \%$. Network of fuel consumption and at the current time obtained are presented in Table 3.

Table 3. Results.

\begin{tabular}{|l|l|l|l|}
\hline \multicolumn{1}{|c|}{ Time period } & stops and delays & \multicolumn{1}{|c|}{$\begin{array}{c}\text { queues and conges- } \\
\text { tion }\end{array}$} & fuel consumption \\
\hline $\begin{array}{l}\text { 08:00-09:00 } \\
\text { (the existing } \\
\text { regime) }\end{array}$ & 260,99 & 134,29 & 130,34 \\
\hline $\begin{array}{l}\text { 08:00-09:00 } \\
\text { (the proposed } \\
\text { regime) }\end{array}$ & 210,99 & 121,02 & 109,15 \\
\hline
\end{tabular}

\section{Conclusion}

In terms of regional centers, where the conduct of difficult technical and urban activities, the most promising direction of combat vehicles delays is to build the ITS with the obligatory presence of a transport monitoring subsystem on the advanced features of traffic flow.

As a result of the introduction of these systems solve the basic problems of regional centers: reduced vehicle delays; reduce the number of unintended stops at intersections; improved environmental performance; partially or completely eliminated congestion in the busiest sections of road networks; reduced the number of traffic accidents.

Using the improved method in the implementation of intelligent transport systems in particular - adaptive traffic control will increase the efficiency of traffic management in the implementation of coercive control. Permanent monitoring of the transport network using traffic detectors and the accumulation of a database, to determine the value offered for the use of the presence of factors and adapt management to the real conditions.

\section{References}

1. Transport Strategy of the Russian Federation for the period up to 2030: the disposal of the Russian Government dated June 11, 2014 № 1032-p, 110. [Electronic resource] / Ministry of Transport website. - Access: http://www.mintrans.ru/documents/\#document_22371, free

2. The Federal Target Program "Development of Transport System of Russia (20102020)" [Electronic resource] / Site Russia federal target program. - Access: http://fcp.economy.gov.ru/cgi-bin/cis/fcp.cgi/Fcp/ViewFcp/View/2014/264/, free

3. The public declaration of the key objectives and priorities of the Ministry of Transport of the Russian Federation 2014 [electronic resource] / Website Ministry of Transport of the Russian Federation - Access: http://www.mintrans.ru/, free

4. Delegation of the European Union in Russia [Electronic resource] / European Union. Access: 
http://eeas.europa.eu/delegations/russia/eu_russia/fields_cooperation/transport/index_r u.htm, free

5. Brussels, 28.3.2011 COM (2011) 144 final Roadmap to a Single European Transport Area - Towards a competitive and resource efficient transport system

6. Intelligent transport systems [electronic resource] / Website European Commission. Access: http://ec.europa.eu/transport/themes/its/road/action_plan/, free

7. The federal target program "Increase of traffic safety in 2013-2020 years" [Electronic resource] / - Access mode: http://www.fcp-pbdd.ru/, free

8. TRANSYT 14 TRL Copyright TRL Limited 2010, 2011. TRANSYT 14 user guide July 2012, Issue J (to accompany TRANSYT 14.1.2) ISSN 1365-6929

9. Information on the terms of the road safety [electronic resource] / Website Traffic police - Access: http://www.gibdd.ru/stat/, free

10. V.F. Yakovlev Tutorial on the device of the car // Moscow "Third Rome" - 78 (2008).

11. I.N. Porvatov, S.R. Crystal Classification and labeling of cars, methodical instructions to practical studies on discipline "Fundamentals of car design" MADI // M 50.

12. A.N. Novikov, A.L. Sevostyanov, A.A. Katunin, A.V. Kulev The use of intelligent transport systems (ITS) for improving the efficiency of urban public transport, The world of transport and technological machines. Number 1, (40). S. 85-90 (2013)

13. A.N. Novikov, A.A. Katunin, V.V. Vasiliev, D.D. Matnazarov "Intellectualization of traffic on the highway outside the city Orla Naugorskoe" In: GLONASS - the region under the general editorship of A. Novikova. Eagle, S. 48-54 (2014)

14. A.E. Borovskoy, I.A. Novikov, A.G. Shevtsova The introduction of intelligent transport systems within the framework of national programs to improve road safety, Bulletin of Kharkiv National Automobile and Highway University. № 61-62. Pp 279283 (2013)

15. J. Olander, Winter Index by using RWI and MESAN: XI International Winter Road Congress, Sapporo, Japan, 28-31 January 2002. Sapporo. (2002)

16. E. Frolova, D. Kondakov, V. Orlova, L. Avdyushkina, A. Bykov, V. Danilov. Design of deicing reagents based on alkali and alkaline-earth metals and ammonium formates, acetates, and nitrates. Theoretical Foundations of Chemical Engineering. July, Volume 47, Issue 4, pp 422-427 (2013)

17. Zhichao Zhu, Z., J. Xiang, J. Wang, D. Qiu. Effect of polyvinyl alcohol on ice formation in the presence of a liquid/solid interface. Langmuir, 33 (1), pp 191-196 (2017)

18. Superpave Performance Graded Asphalt Binder Specification and Testing. Asphalt Institute Superpave. Series No 1 (SP-1). 67 p (1997)

19. A Shevtsova, I. Novikov, A. Borovskoy Research of influence of time of reaction of driver on the calculation of the capacity of the highway. Transport problems Volume 10 Issue 3 pp 53 - 59.

20. A. Novikov, I. Novikov, A. Katunin, A. Shevtsova. Adaptation Capacity of the Traffic Lights Control System (TSCS) as to Changing Parameters of Traffic Flows Within Intellectual Transport Systems (ITS) Transportation Research Procedia 20 pp. 455 462 (2017).

21. A. Novikov, I. Novikov, A. Shevtsova (2017) Study of the impact of type and condition of the road surface on parameters of signalized intersection. Transportation Research Procedia 36 pp. 548-555 (2018) 